\title{
GRASSLAND DIVERSITY AND PRODUCTIVITY: THE INTERPLAY OF RESOURCE AVAILABILITY AND PROPAGULE POOLS
}

\author{
Bryan L. Foster ${ }^{1}$ AND TIMOthy L. Dickson \\ Department of Ecology and Evolutionary Biology, University of Kansas, Lawrence, Kansas 66045-7534 USA
}

\begin{abstract}
Processes operating at multiple spatial scales govern the structure and functioning of ecological communities. We conducted a resource manipulation and propagule addition experiment in grassland to evaluate the interaction of local resource availability and propagule pools in governing local-scale plant colonization, biodiversity, and aboveground productivity. The availabilities of establishment microsites and water were manipulated in field plots for two years through the application of experimental soil disturbances and irrigation, respectively. Resource manipulations led to increased invasibility of the community, as predicted by the theory of fluctuating resources. Rates of colonization, enhanced by the sowing of 32 grassland species, increased plant diversity and aboveground productivity, but to a greater extent under conditions of resource enrichment. Although resource enrichment generally increased diversity and productivity, these responses were contingent upon species availability and tended to be more pronounced in the presence of an expanded propagule pool. These findings suggest that biodiversity at the level of the available propagule pool and fluctuations in resources interact to regulate local resident diversity and productivity by determining opportunities for species sorting, by mediating community assembly, and by governing the potential for functional compensation in the community.
\end{abstract}

Key words: colonization; diversity; grassland; invasibility; productivity; propagule pools; resource availability.

\section{INTRODUCTION}

The emergent properties of communities are governed by processes operating at multiple spatial scales (Holling 1992). However, much of community ecology has traditionally focused on localized ecological phenomena (i.e., species interactions) and niche relations in regulating community structure (Grime 1979, Tilman 1982, Ricklefs 1987, Cornell and Lawton 1992, Zobel 1997). There is a growing realization that dispersal limitations and regional constraints on local species availability can restrict colonization rate and thus diversity under some conditions (Eriksson 1993, Tilman 1997, Huston 1999, Zobel et al. 2000, Foster 2001). As a result, there is substantial interest in understanding how the interplay of local ecological processes, inter-neighborhood dispersal, and regional species pools may govern community structure and function (Leibold et al. 1997, Zobel 1997, Huston 1999, Foster 2001, Loreau et al. 2003). To the extent that species pools and dispersal limitations control local diversity and/or functional composition in the community, ecosystem processes may be affected (Hobbie 1992, Naeem et al. 1994, Hooper and Vitousek 1997, Hector et al. 1999, Tilman et al. 2001, Downing and Leibold 2002). Therefore, anthropogenic changes to regional species pools may have important consequenc-

Manuscript received 17 November 2003; revised 7 December 2003; accepted 3 February 2004. Corresponding Editor: M. J. Lechowicz.

${ }^{1}$ E-mail: bfoster@ku.edu es for both community and ecosystem processes (Grime 1998, Loreau et al. 2003).

Several studies have shown that some unproductive grasslands are readily colonized by new species such that diversity is limited by propagule availability (Pärtel et al. 1996, Tilman 1997, Zobel et al. 2000, Foster 2001, Foster and Tilman 2003). Other studies suggest that the degree to which colonization and diversity are limited by propagule availability, vs. local niche limitation, varies predictably along gradients of resource supply and productivity (Huston 1999, Pärtel et al. 2000, Foster 2001). More generally, spatial and temporal variation in community invasibility should be determined by spatial and temporal variation in the availability of free resources as governed by the balance of resource supply and demand (Burke and Grime 1996, Davis et al. 2000). Because resource availability in grasslands of the Great Plains varies substantially within and between years due to variation in resource supply (wet vs. dry years, for example) or due to periodic disturbances (Knapp and Seastedt 1998), a local community may experience periodic windows of opportunity for colonization, separated by periods when the invasibility of the community is limited by a close match between resource supply and demand (Seastedt and Knapp 1993, Davis et al. 2000). Although windows of opportunity may arise periodically, the extent to which they actually enhance rates of colonization and produce changes at the community or ecosystem level following a window's closure may depend upon prop-

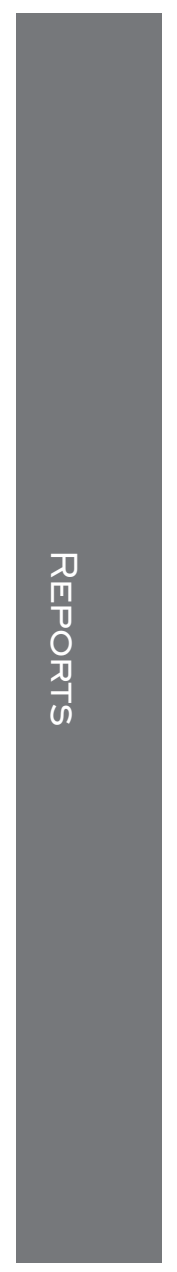


agule supply and the diversity of colonists available to exploit temporary resource surpluses.

We conducted a field experiment in Kansas grassland to (1) evaluate impacts of resource enrichment on community invasibility and (2) evaluate the interplay of resource conditions and propagule availability in regulating local colonization, diversity, and aboveground productivity. Over two growing seasons, we manipulated two potentially critical plant resources in field plots: establishment microsites and water. Additionally, we manipulated the availability of colonists to plots over the same period via experimental sowing of 32 grassland species. We present data from year three of the experiment, the year following cessation of the experimental manipulations, to gauge the impact of a prior window of resource opportunity on subsequent community and ecosystem properties.

\section{Methods \\ Study site}

The study was conducted at the Nelson Environmental Studies Area (NESA; University of Kansas), which is located in northeastern Kansas. The experiment was established on a relatively unproductive ridgetop within a 20 -ha, secondary grassland dominated by the perennial grasses Bromus inermis Leyss. (introduced $\mathrm{C}_{3}$ grass), Festuca arundinaceae Schreb. (introduced $\mathrm{C}_{3}$ grass), and Poa pratensis $\mathrm{L}$. (introduced $\mathrm{C}_{3}$ grass). Although the site has a long history of use as cropland, it was maintained as a seeded hayfield (Brome and Fescue) for at least 20 years prior to abandonment in 1984 (Foster et al. 2002). Soils are Pawnee clay loam and Grundy silty clay loam (montmorillonitic, mesic Aquic Argiudolls). Climate of the region is humid continental with a mean annual temperature of $12.9^{\circ} \mathrm{C}$ and mean annual precipitation of $930 \mathrm{~mm}$. The seasonal distribution of precipitation is unimodal, peaking in June (Kettle and Whittemore 1991).

\section{Experimental design}

In November 1999 , we established an $8 \times 8$ grid of $641-\mathrm{m}^{2}$ plots with $2-\mathrm{m}$ walkways. Each north-south row of eight plots constitutes an experimental block. To each block, we randomly applied a $2 \times 2 \times 2$ factorial set of treatments including manipulations of soil disturbance (disturbance to alter abundance of establishment microsites vs. no disturbance), water availability (irrigation vs. no irrigation), and availability of colonists (seeds sown of 32 species vs. seeds not sown). The application of experimental disturbances and the sowing of seeds took place in February 2000 and 2001 (treatment years). Disturbances were applied by raking to scarify the soil and remove litter. Raking mimicked small-scale disturbances inherent to this grassland caused by small-mammal activity and soil expansioncontraction (Foster et al. 2002). Plots were irrigated from May through October in 2000 and 2001. The pur- pose of irrigation was to increase water supply just enough to reduce drought stress during the growing season. To achieve this, a volume of water equivalent to a moderate rainfall event $(\sim 12.7 \mathrm{~mm})$ was added whenever four days passed without measurable precipitation. Plots were irrigated using a hand sprayer and garden hose attached to a water truck.

All sown species are members of the regional pool and are found within $2 \mathrm{~km}$ of the study site (Foster 2001). Fourteen of these species were present within the broader 20-ha field site at the start of the study, but only two were present initially at low abundance in some plots. Sown species represent a range of life histories, functional groups, historical origins, and habitat affinities (Appendix). Seeds were obtained from regional seed suppliers (Stock Seed Company, Murdock, Nebraska, USA; Delange Seed Company, Sedgwick, Kansas, USA) and added by hand at a rate of 400 seeds/ $\mathrm{m}^{2}$ for each species.

\section{Measurements and analyses}

Percent cover surveys were conducted in midsummer (2-3 July) and fall (5-6 October) 2002. Calibrations of cover estimates were facilitated by comparing species abundances in plots to variously sized cardboard cutouts of known area. Cover was evaluated for each species independently so that the sum of cover values could exceed $100 \%$ and reflect canopy layering. Canopy interception of photosynthetically active radiation (percentage of PAR intercepted) was measured at peak biomass in mid July 2002 using a 0.8-m PAR ceptometer probe (Decagon Devices, Pullman, Washington, USA). For each plot, five measurements were taken below and above the canopy such that PAR interception could be expressed as a percentage of full sun ([1 (PAR below canopy/PAR above canopy)] $\times 100$ ). In July 2002, plant heights were measured with a meter stick in each plot at nine points and then averaged to obtain an average canopy value.

Midsummer and fall cover data were combined to calculate indices of community invasibility and diversity. Although the term "invasibility" carries with it the connotation of invasion by exotic species, we use the term here in its general sense to refer to a community's openness to colonization, whether by native or introduced species. Invasibility of sown plots was measured using two indices: $I_{\mathrm{S}}$, which measured the proportion of sown species present in sown plots in 2002; and $I_{\mathrm{A}}$, which measured the aggregate abundance (percent cover) of sown species in 2002. Species richness $(S)$ was calculated as the cumulative number of species observed in a plot in both surveys. Peak cover values for each species (cover in mid or late summer, whichever was greater) were used to calculate Shannon diversity $\left(H^{\prime}\right)$ and evenness $(E)$. Functional group diversity $\left(H_{\mathrm{FG}}^{\prime}\right)$ was calculated as Shannon diversity for species grouped by functional classification: $\mathrm{C}_{3}$ gra- 
minoids, $\mathrm{C}_{4}$ graminoids, forbs, legumes, and woody plants.

Plant productivity was examined by using three nondestructive surrogate measures of aboveground production in 2002: PAR interception, canopy height, and total vegetative cover. These surrogate measures were used, instead of plant biomass, in order to avoid destruction of the plots. While PAR interception and canopy height measured canopy characteristics at peak standing crop, vegetative cover provides a seasonally integrated index of aboveground productivity because it reflects the sum of species peak cover across early and late surveys (Stevens and Carson 2001). Elsewhere within our 20-ha field site, PAR interception, canopy height, and total vegetative cover are all significantly correlated with standing crop biomass, leaf area index, and a normalized difference vegetation index (NDVI) derived from remote sensing (Foster et al., in press; M. E. Ramspott, unpublished manuscript).

For all data analyses, we used type III factorial ANOVA for randomized block designs (performed using SPSS software, Version 11.5; SPSS, Chicago, Illinois, USA). To satisfy assumptions of ANOVA, $\log _{10}$ transformations were applied to cover data. Nomenclature follows Great Plains Flora Association (1986).

\section{RESULTS}

Of the 32 species sown, 25 were present in at least one of the 32 sown plots in 2002, while only two were present at low abundances in a small number of the non-sown plots (Appendix). The most abundant sown species in sown plots (species with cover values $>1 \%$ ) were all native and included Monarda fistulosa (perennial forb, mean cover $=25.4 \%$, plot occupancy $=$ $56 \%$ ), Salvia azurea (perennial forb, mean cover $=$ $3.6 \%$, plot occupancy $=69 \%)$, Panicum virgatum $\left(\mathrm{C}_{4}\right.$ perennial grass, mean cover $=3.4 \%$, plot occupancy $=59 \%$ ), Lespedeza capitata (perennial legume, mean cover $=2.2 \%$, plot occupancy $=50 \%)$, Rudbeckia hirta (perennial forb, mean cover $=1.9 \%$, plot occupancy $=34 \%)$, and Andropogon gerardi $\left(\mathrm{C}_{4}\right.$ perennial grass, mean cover $=1.1 \%$, plot occupancy $=50 \%$ ).

The proportion of sown species present in sown plots, $I_{\mathrm{S}}$, was increased by disturbance (Fig. 1A), while the aggregate abundance (percent cover) of sown species, $I_{\mathrm{A}}$, was increased additively by both disturbance and irrigation (Fig. 1B). The influences of disturbance and irrigation on $I_{\mathrm{A}}$ largely reflect positive responses of the most abundant sown forb, Monarda fistulosa (disturbance, $F_{1,21}=8.42, P<0.01$; irrigation, $F_{1,21}=$ $71.59, P<0.01$ ), and an abundant sown $\mathrm{C}_{4}$ grass, Panicum virgatum (disturbance, $F_{1,21}=12.05, P<0.01$; irrigation, $\left.F_{1,21}=12.95, P<0.01\right)$.

Effects of resource conditions on plot invasibility and colonization from the expanded propagule pool produced significant impacts on diversity (Fig. 2A-D). Shannon diversity $\left(H^{\prime}\right.$; Fig. 2A) was increased by disturbance, irrigation, and sowing. A significant inter-
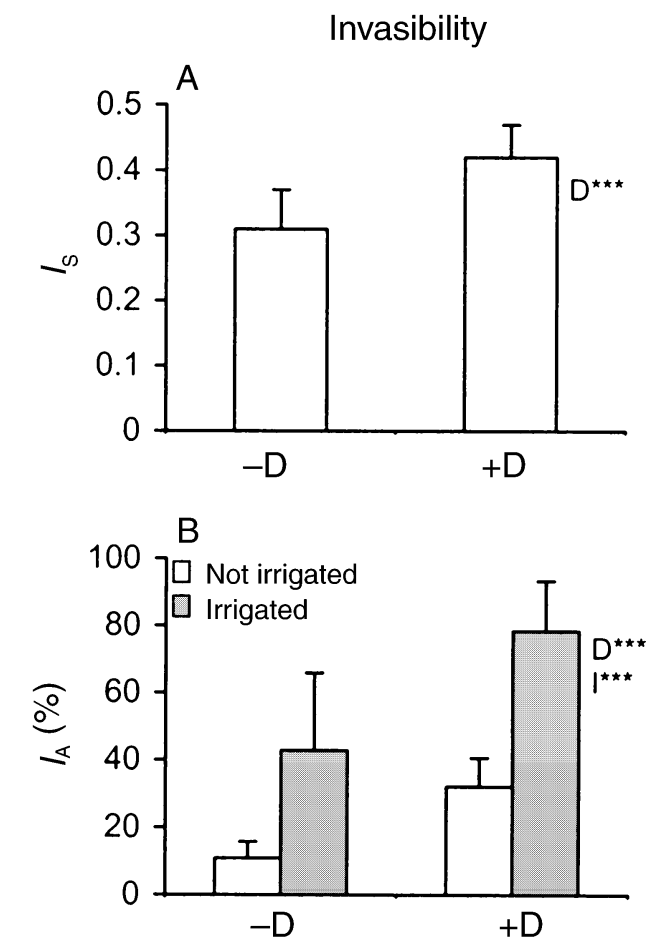

FIG. 1. Effects of experimental manipulations (mean +1 $\mathrm{SD})$ on two indices of community invasibility measured in the sown plots in 2002. (A) $I_{\mathrm{S}}$ represents the proportion of sown species present in sown plots. (B) $I_{\mathrm{A}}$ represents the aggregate percent cover of all sown species present in the sown plots. D refers to disturbance level ( $-\mathrm{D}$, plots not disturbed; +D, plots disturbed).

$* P<0.05 ; * * P<0.01 ; * * * P<0.001$.

action between disturbance and sowing indicated that the positive effects of disturbance on $H^{\prime}$ were manifest only in sown plots (disturbance effect in sown plots, $F_{1,21}=11.71, P<0.01$; disturbance effect in unsown plots, $\left.F_{1,21}=0.54, P>0.05\right)$ and that sowing had the greatest positive impact on $H^{\prime}$ in disturbed plots (sowing effect in disturbed plots, $F_{1,21}=47.81, P<0.001$; sowing effect in nondisturbed plots, $F_{1,21}=11.18, P$ $<0.01$ ). Species richness (Fig. 2B) was increased additively by disturbance, irrigation, and sowing. Evenness (Fig. 2C) was increased by disturbance, irrigation, and sowing. A significant interaction between disturbance and sowing indicated that effects of disturbance on $E$ were manifest only in sown plots (disturbance effect in sown plots, $F_{1,21}=7.89, P<0.05$; disturbance effect in unsown plots, $F_{1,21}=0.13, P>0.05$ ) and that sowing had the greatest positive impact on $E$ in disturbed plots (sowing effect in disturbed plots, $F_{1,21}=$ 26.78, $P<0.001$; sowing effect in nondisturbed plots, $\left.F_{1,21}=4.86, P<0.05\right)$. Functional group diversity ( $H_{\mathrm{FG}}^{\prime}$; Fig. 2D) was increased additively by disturbance, sowing, and irrigation.

The community-level consequences of the experimental treatments extended to the ecosystem level by indirectly affecting measures of aboveground produc- 
Diversity
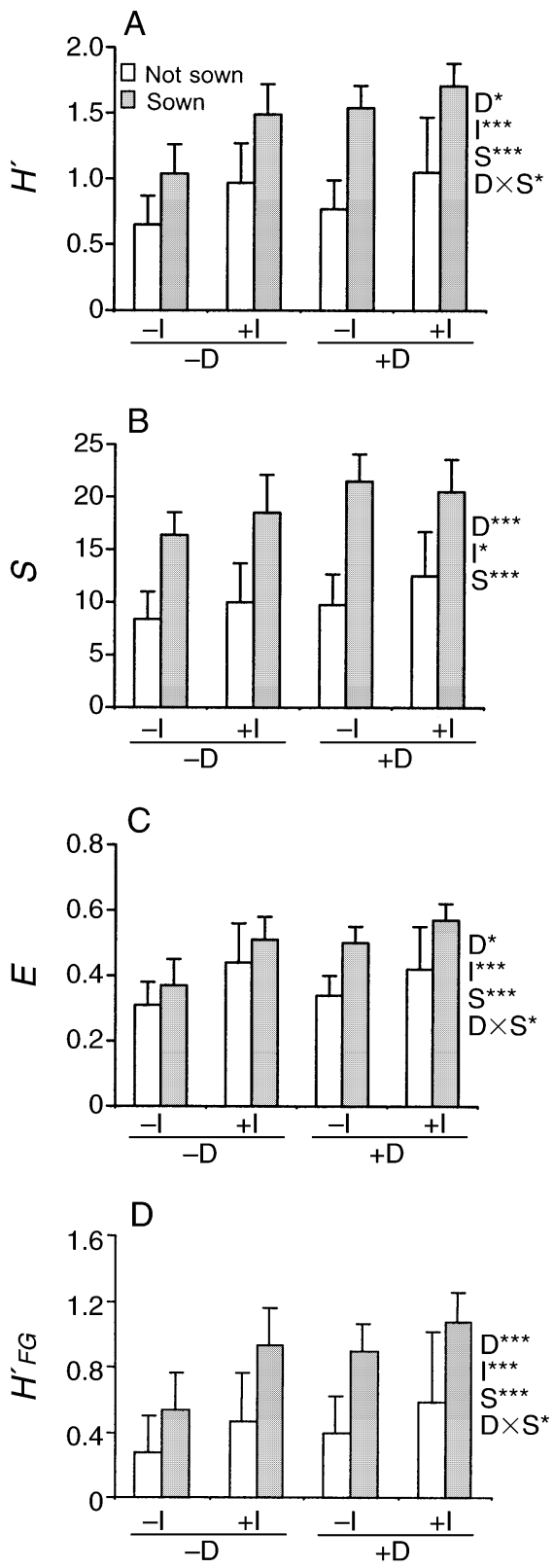

Productivity
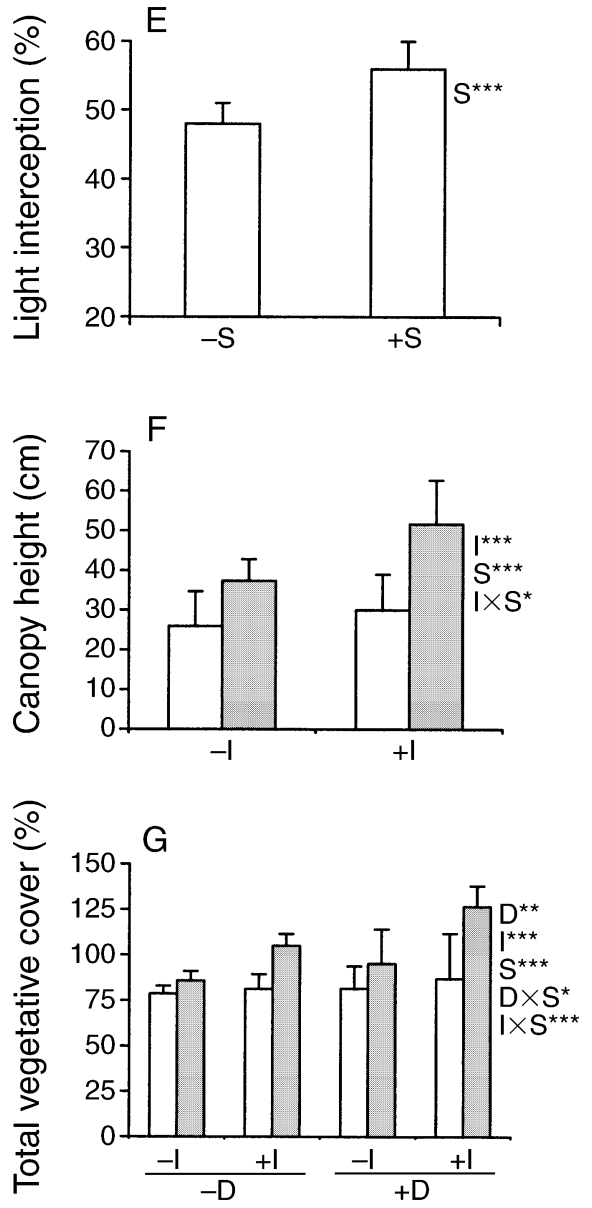

FIG. 2. Effects of experimental manipulations (mean $+1 \mathrm{SD}$ ) on measures of plant diversity and productivity: (A) Shannon diversity $\left(H^{\prime}\right),(\mathrm{B})$ species richness $(S),(\mathrm{C})$ evenness $(E),(\mathrm{D})$ functional group diversity $\left(H_{\mathrm{FG}}^{\prime}\right)$, (E) light interception, $(\mathrm{F})$ canopy height, and $(\mathrm{G})$ total vegetative cover. D refers to disturbance level $(-\mathrm{D}$, plots not disturbed; $+\mathrm{D}$, plots disturbed). I refers to irrigation level ( $-\mathrm{I}$, plots not irrigated; $+\mathrm{I}$, plots irrigated). In $(\mathrm{E}), \mathrm{S}$ refers to level of sowing ( $-\mathrm{S}$, plots not sown, $+\mathrm{S}$, plots sown). The significance of treatments is indicated as follows: $* P<0.05 ; * * P<0.01 ; * * * P<0.001$.

tivity (Fig. 2E-G). PAR interception (Fig. 2E) was increased by sowing, but was unaffected by irrigation and disturbance. Canopy height (Fig. 2F) was increased by irrigation and sowing. A significant interaction between irrigation and sowing indicated that irrigation increased canopy height significantly only in plots that had been sown (irrigation effect in sown plots, $F_{1,21}=$ $21.40, P<0.001$; irrigation effect in unsown plots,
$\left.F_{1,21}=1.39, P>0.05\right)$, and that sowing had the greatest positive impact on canopy height in irrigated plots (sowing effect in irrigated plots, $F_{1,21}=42.27, P<$ 0.001 ; sowing effect in nonirrigated plots, $F_{1,21}=$ 17.53, $P<0.001$ ). Total vegetative cover (Fig. 2G) was increased by disturbance, irrigation, and sowing. However, significant interactions among disturbance, sowing, and irrigation indicated that effects of distur- 
bance and irrigation on total cover were manifest only in sown plots (disturbance effect in sown plots, $F_{1,21}$ $=4.55, P<0.05$; disturbance effect in unsown plots, $F_{1,21}=0.57, P>0.05$; irrigation effect in sown plots, $F_{1,21}=34.40, P<0.001$; irrigation effect in unsown plots, $\left.F_{1,21}=3.16, P>0.05\right)$. These significant interaction terms also indicate that the effect of sowing on total cover was greater in disturbed plots than nondisturbed plots (sowing effect in disturbed plots, $F_{1,21}=$ 13.27, $P<0.01$; sowing effect in nondisturbed plots, $\left.F_{1,21}=7.32, P<0.05\right)$, and greater in irrigated than nonirrigated plots (sowing effect in irrigated plots, $F_{1,21}$ $=39.25, P<0.001$; sowing effect in nonirrigated plots, $\left.F_{1,21}=3.93, P<0.06\right)$.

\section{DISCUSSION}

Our results show that colonization, diversity, and aboveground productivity in this grassland are strongly limited by the availability of resources and by the pool of colonists available to exploit those resources. Our findings suggest that the degree to which propagule pools constrain community and ecosystem properties may be contingent upon the invasibility of the local community as governed by fluctuations in resources (e.g., Davis et al. 2000).

In grasslands of the Great Plains, resource availability varies substantially within and among years (Seastedt and Knapp 1993, Knapp and Seastedt 1998). Intra- and interannual variability in rainfall, for example, is an important determinant of temporal fluctuations in recruitment, growth, diversity, and primary production in grasslands (Pitt and Heady 1978, Tilman and El Haddi 1992, Tilman and Downing 1994, Knapp and Seastedt 1998). The form and intensity of disturbance in grasslands may also vary considerably within and between years, producing fluctuations in the availability of establishment sites, soil nutrients, and light (Platt 1975, Hobbs and Mooney 1985, Carson and Pickett 1990, Briggs and Knapp 1995, Davis et al. 2000). In this study, irrigation and experimental disturbance mimicked a natural window of resource opportunity. The two-year period over which the experimental manipulations were applied encompassed a year of moderate drought (2000; precipitation $194 \mathrm{~mm}$ below the annual mean) and a year of normal precipitation (2001; precipitation $12 \mathrm{~mm}$ below the annual mean), providing reasonable background conditions to assess impacts of resource enrichment. Consistent with the theory of fluctuating resources (Davis et al. 2000), we found that invasibility was greatest when water and soil microsites were most plentiful, illuminating the joint importance of water availability and small-scale soil disturbances in regulating establishment, and thus community invasibility.

Manipulations of resources and propagule availability acted either additively or interactively to impact community diversity. Irrigation led to an increase in Shannon diversity $\left(H^{\prime}\right)$ that was not contingent upon either disturbance or propagule availability. However, effects of disturbance and sowing on $H^{\prime}$ were contingent upon each other. Sowing increased $H^{\prime}$ in disturbed and nondisturbed plots, but to a greater extent in disturbed plots, indicating that the degree to which propagule availability controlled diversity was contingent upon the resources made available by disturbance. These contingent responses of $H^{\prime}$ arose through effects on community evenness, not species number as illustrated by the purely additive effects of the experimental factors on species richness.

The three surrogate measures of aboveground productivity were all enhanced by propagule input. However, for two of these measures, effects of propagule availability were contingent on resource levels. We found that vegetative cover, a seasonally integrated index of aboveground productivity, was enhanced by disturbance and irrigation, but only in plots that had been sown. Sowing increased vegetative cover under all circumstances, but to a greater extent in the presence of enhanced resources. Canopy height was enhanced by irrigation and sowing. However, effects of irrigation on canopy height were manifest only in sown plots. Sowing increased canopy height in irrigated and non-irrigated plots, but to a greater extent in irrigated plots. In contrast to responses of total cover and canopy height, PAR interception was increased only by sowing, reflecting a significant contribution of sown species to canopy energy capture that was independent of resource manipulations.

Our findings contrast with Wilsey and Polley (2003) who found no effect of seed addition on diversity and productivity in subhumid Texas grasslands. The lack of response in that study may reflect lower water availability (lower annual rainfall and hotter, dryer summers) than eastern Kansas. Although Wilsey and Polley (2003) found positive effects of seed addition on seedling emergence, almost all seedlings died during the hottest and driest months, thus producing no effect on diversity or productivity. Differences between our study and Wilsey and Polley (2003) may reflect the importance of regional climate in determining the relative significance of propagule availability to the regulation of community structure.

The effects of sowing on diversity and aboveground productivity observed here are consistent with the findings of several experimental studies that had directly manipulated plant diversity as an independent variable via random species selections from defined species pools (Naeem et al. 1996, Tilman et al. 1996, 2001, Hector et al. 1999). The positive associations found between diversity and productivity in these previous experiments have been criticized as sampling artefacts (Aarssen 1997, Huston 1997, Wardle 1999, Smith and Knapp 2003), the argument being that community assembly in nature is a distinctly nonrandom process that draws community members from a species pool in a biased manner as dictated by biotic filtering processes.

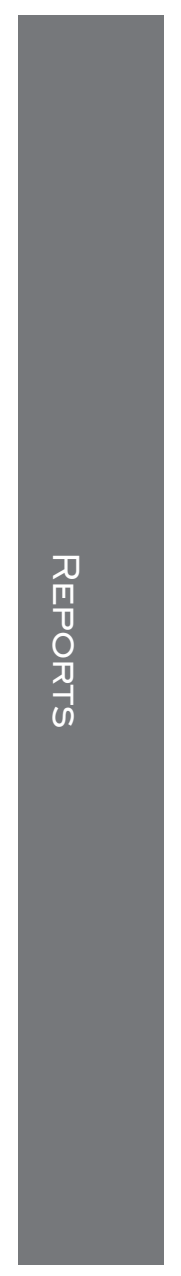


Our results are particularly compelling in light of these previous studies because they illustrate how local biodiversity and productivity may be influenced by sorting of a species pool via local biotic filtering, rather than via selection by the experimenter.

We do not wish to argue that the greater aboveground productivity observed in our sown plots was necessarily the direct result of increased plot diversity per se, as has been argued for other biodiversity studies. Instead, we suggest that these impacts reflect the ecological sampling of an expanded propagule pool by the community itself as governed by natural sorting processes, resulting in the selection of several productive species of complimentary phenology. Diverse propagule pools are more likely to contain productive species than depauperate propagule pools (Aarssen 1997, Huston 1997), and provide a greater variety of functional traits to exploit the array of resource opportunities available during the year. Although this grassland is inhabited by a number of functional groups, cool-season $\left(\mathrm{C}_{3}\right)$ grasses predominate. Exposure of plots to a larger propagule pool than is typically available increased functional group diversity and enhanced representation by species that peak in abundance at different times of year (legumes, non-legume forbs, and $\mathrm{C}_{4}$ grasses), thus complimenting the growth of $\mathrm{C}_{3}$ grasses. The abundant sown species, Monarda fistulosa and Rudbeckia hirta (non-leguminous forbs) were more abundant midsummer than fall $(P<0.05$; paired $t$ test). Other abundant sown species-Salvia azurea (non-leguminous forb), Lespedeza capitata (leguminous forb), Andropogon gerardii $\left(\mathrm{C}_{4}\right.$ grass), and Panicum virgatum $\left(\mathrm{C}_{4}\right.$ grass $)$ - were more abundant in fall than midsummer $(P<0.05)$. These findings suggest that species and functional group diversity at the level of the available propagule pool can influence local productivity by governing community assembly, and thus opportunities for species selection and functional complimentarity.

A community's response to temporal windows of resource opportunity may be contingent upon the composition and diversity of the available propagule pool, reflecting interplay between local and regional processes that influence colonization, biodiversity and ecosystem function. We suggest that much of the variation in grassland structure and function observed within landscapes, but which is left unexplained by local ecological processes and underlying environmental gradients, can be explained by heterogeneity of the propagule pools from which local assemblages are formed. Variable propagule pools may be generated by heterogeneous landscape histories, variable seed production, extrinsic and intrinsic barriers to dispersal, species introductions, and habitat destruction and fragmentation (Primack and Miao 1992, Pacala and Levin 1997, Tilman et al. 1997, Foster 2001). Broadly, our findings suggest that changes in diversity at the scale of the regional species pool will alter opportunities for ecological sorting and community assembly at the local scale, thus affecting local diversity and the functional responses of communities to fluctuating resources (Grime 1998, Davis et al. 2000, Loreau et al. 2003). Although much discussion has focused on the potential consequences of species loss for ecosystem function, recent work indicates that regional species pools may be increasing in many locations as a result of human introductions of species (Davis 2003, Sax and Gaines 2003). Our results provide insight into how either increases or decreases in regional species pools may feed back to impact local community and ecosystem properties. We suggest that in natural communities the influence of changes in biodiversity on ecosystem function cannot be fully understood in isolation from an understanding of the multiscaled assembly processes that govern regional species pools and local species coexistence.

\section{ACKNOWLEDGMENTS}

We thank H. Glaholt, T. Hildebrand, I. Karel, G. Loving, S. Martin, C. Murphy, T. Peterson, A. Ross, and D. Ross for their assistance in the field. We thank D. Kettle, G. Pittman, and B. Johanning for logistical support. We are grateful to M. Davis, J. Knops, C. Murphy, E. Questad, and one anonymous reviewer for comments made on drafts of the manuscript. This research was funded by a University of Kansas General Research Fund Award and the National Science Foundation (DEB01-08302).

\section{Literature Cited}

Aarssen, L. W. 1997. High productivity in grassland ecosystems: effected by species diversity or productive species? Oikos 80:183-184.

Briggs, J. M., and A. K. Knapp. 1995. Interannual variability in primary production in tallgrass prairie: climate, soil moisture, topographic position, and fire as determinants of aboveground biomass. American Journal of Botany 82: 1024-1030.

Burke, M. J. W, and J. P. Grime. 1996. An experimental study of plant community invasibility. Ecology 77:776-790.

Carson, W., and S. T. A. Pickett. 1990. Role of resources and disturbance in the organization of an old-field plant community. Ecology 71:226-238.

Cornell, H. V., and J. H. Lawton. 1992. Species interactions, local and regional processes, and limits to the richness of ecological communities: a theoretical perspective. Journal of Animal Ecology 61:1-12.

Davis, M. A. 2003. Biotic globalization: does competition from introduced species threaten biodiversity? BioScience 53:481-489.

Davis, M. A., J. P. Grime, and K. Thompson. 2000. Fluctuating resources in plant communities: a general theory of invasibility. Journal of Ecology 88:528-534.

Downing, A. L., and M. A. Leibold. 2002. Ecosystem consequences of species richness and composition in pond food webs. Nature 416:837-841.

Eriksson, O. 1993. The species pool hypothesis and plant community diversity. Oikos 68:371-374.

Foster, B. L. 2001. Constraints on colonization and species richness along a grassland productivity gradient: the role of propagule availability. Ecology Letters 4:530-535.

Foster, B. L., T. D. Dickson, C. A. Murphy, I. S. Karel, and V. H. Smith. In press. Propagule pools mediate community assembly and diversity-ecosystem regulation along a grassland productivity gradient. Journal of Ecology.

Foster, B. L., V. H. Smith, T. L. Dickson, and T. Hildebrand. 2002. Invasibility and compositional stability in a grass- 
land community: relationships to diversity and extrinsic factors. Oikos 99:301-308.

Foster, B. L., and D. Tilman. 2003. Seed limitation and the regulation of community structure in oak savanna grassland. Journal of Ecology 9:999-1007.

Great Plains Flora Association. 1986. Flora of the Great Plains. University Press of Kansas, Lawrence, Kansas, USA.

Grime, J. P. 1979. Plant strategies and vegetation processes. Wiley, New York, New York, USA.

Grime, J. P. 1998. Benefits of plant diversity to ecosystems: immediate, filter and founder effects. Journal of Ecology 86:902-910.

Hector, A. et al. 1999. Plant diversity and productivity experiments in European grasslands. Science 286:1123-1127.

Hobbie, S. 1992. Effects of plant species on nutrient cycling. Trends in Ecology and Evolution 7:336-339.

Hobbs, R. J., and H. A. Mooney. 1985. Community and population dynamics of serpentine annual grassland in relation to gopher disturbances. Oecologia 67:342-351.

Holling, C. S. 1992. Cross-scale morphology, geometry, and dynamics of ecosystems. Ecological Monographs 62:447502.

Hooper, D. U., and P. M. Vitousek. 1997. The effects of plant composition and diversity on ecosystem processes. Science 277:1302-1305.

Huston, M. A. 1997. Hidden treatments in ecological experiments: re-evaluating the ecosystem function of biodiversity. Oecologia 108:449-460.

Huston, M. A. 1999. Local processes and regional patterns: appropriate scales for understanding variation in the diversity of plants and animals. Oikos 86:3393-3401.

Kettle, W. D., and D. O. Whittemore. 1991. Ecology and hydrogeology of the Kansas Ecological Reserves and the Baker Wetlands. University of Kansas, Lawrence, Kansas, USA.

Knapp, A. K., and T. R. Seastedt. 1998. Grasslands, Konza Prairie and long-term ecolgical research. Pages 10-32 in A. K. Knapp, J. M. Briggs, D. C. Hartnett, and S. L. Collins, editors. Grassland dynamics. Oxford University Press, Oxford, UK.

Leibold, M. A., J. M. Chase, J. B. Shurin, and A. L. Downing. 1997. Species turnover and the regulation of trophic structure. Annual review of ecology and systematics 28:467494.

Loreau, M., N. Moquet, and R. D. Holt. 2003. Meta-ecosystems: a theoretical framework for a spatial ecosystem ecology. Ecology Letters 6:673-679.

Naeem, S., K. Hakansson, J. H. Lawton, M. J. Crawley, and L. J. Thompson. 1996. Biodiversity and plant productivity in a model assemblage of plant species. Oikos 76:259-264.

Naeem, S., L. J. Thompson, S. P. Lawler, J. H. Lawton, and R. M. Woodfin. 1994. Declining biodiversity can alter the performance of ecosystems. Nature 368:734-737.

Pacala, S. W., and S. A. Levin. 1997. Biologically generated spatial pattern and the coexistence of competing species. Pages 204-232 in D. Tilman and P. Kareiva, editors. Spatial ecology: the role of space in population dynamics and interspecific interaction. Princeton University Press, Princeton, New Jersey, USA.
Pärtel, M., M. Zobel, J. Liira, and K. Zobel. 2000. Species richness limitations in productive and oligotrophic plant communities. Oikos 90:191-193.

Pärtel, M., M. Zobel, K. Zobel, and E. van der Maarel. 1996. The species pool and its relation to species richness: evidence from Estonian plant communities. Oikos 75:111117.

Pitt, M. D., and H. F. Heady. 1978. Responses of annual vegetation to temperature and rainfall patterns in Northern California. Ecology 59:336-350.

Platt, W. J. 1975. The colonization and formation of equilibrium plant associations on badger disturbances in a tallgrass prairie. Ecological Monographs 45:285-305.

Primack, R. B., and S. L. Miao. 1992. Dispersal can limit local plant distribution. Conservation Biology 6:513-519.

Ricklefs, R. E. 1987. Community diversity: relative roles of local and regional processes. Science 235:167-171.

Sax, D. F., and S. D. Gaines. 2003. Species diversity: from global decreases to local increases. Trends in Ecology and Evolution 18:561-566.

Seastedt, T. R., and A. K. Knapp. 1993. Consequences of nonequilibrium resource availability across multiple time scales: the transient maxima hypothesis. American Naturalist 141:621-633.

Smith, M. D., and A. Knapp. 2003. Dominant species maintain ecosystem function with non-random species loss. Ecology Letters 6:509-517.

Stevens, M. H. H., and W. P. Carson. 2001. Phenological complementarity, species diversity, and ecosystem function. Oikos 92:291-296.

Tilman, D. 1982. Resource competition and community structure. Princeton University Press, Princeton, New Jersey, USA.

Tilman, D. 1997. Community invasibility, recruitment limitation, and grassland biodiversity. Ecology 78:81-92.

Tilman, D., and J. A. Downing. 1994. Biodiversity and stability in grasslands. Nature 367:363-365.

Tilman, D., and A. El Haddi. 1992. Drought and biodiversity in grasslands. Oecologia 89:257-264.

Tilman, D., C. L. Lehman, and C. Yin. 1997. Habitat destruction, dispersal, and deterministic extinction in competitive communities. American Naturalist 149:407-435.

Tilman, D., P. B. Reich, J. Knops, D. Wedin, T. Mielke, and C. Lehman. 2001. Diversity and productivity in a longterm grassland experiment. Science 294:843-845.

Tilman, D., D. Wedin, and J. Knops. 1996. Productivity and sustainability influenced by biodiversity in grassland ecosystems. Nature 379:718-720.

Wardle, D. A. 1999. Is "sampling effect" a problem for experiments investigating biodiversity-ecosystem function relationships. Oikos 87:403-407.

Wilsey, B. J., and H. W. Polley. 2003. Effects of seed additions and grazing history on diversity and productivity of subhumid grasslands. Ecology 84:920-931.

Zobel, M. 1997. The relative role of species pools in determining plant species richness: an alternative explanation of species coexistence. Trends in Ecology and Evolution 12:266-269.

Zobel, M., M. Otsus, J. Liira, M. Moora, and T. Mols. 2000. Is small-scale species richness limited by seed availability or microsite availability. Ecology 81:3274-3282.

\section{APPENDIX}

A table of the characteristics of sown species, their occurrence, and percent cover in unsown and sown plots is presented in ESA's Electronic Data Archive: Ecological Archives E085-041-A1. 